\title{
STEREOTYPES AND PREJUDICES AT THE BORDER: AN ATTEMPT AT RAISING INTERCULTURAL AWARENESS THROUGH EXAMPLES FROM THE BULGARIAN AND THE BRITISH MEDIA
}

\author{
Desislava Cheshmedzhieva-Stoycheva*
}

\begin{abstract}
Using a corpus comprised of examples from the Bulgarian and the British print media discourse on the topic of refugees, the paper aims at analyzing the stereotypes and prejudices that are formed and promoted at the encounter of the Other who is culturally and/or religiously different. In addition, the paper looks into the possible attitudes that these stereotypes can provoke towards refugees and the awareness of the image of the cultural Other that they contribute to. The main method of analysis is CDA and the aim is comparing and contrasting the linguistic devices used in both the Bulgarian and the British media on the topic in two different time periods.
\end{abstract}

Key words: media discourse, refugees, stereotypes, $C D A$

\section{Introduction}

Borders are places of conflict and places of division. At the same time, they are also the points where myth and reality collide with an uncertain outcome: sometimes the result of the intercultural encounter serves to disperse the myths, other times it amplifies them and gives rise to prejudice and exhibition of hatred or sometimes even racism.

Nowadays, with the influx of refugees, borders come to regain their significance and more than ever come to be understood as the contested areas where some of the most pervasive ethnic stereotypes get activated mostly triggered by fear for a nation and even a continent's safety. In addition, borders are the places of direct contact with the cultural Other which can provide some insight into the real image of these people.

Media actively cover all developments around the refugee phenomenon. They have the power to both establish and strengthen existing stereotypes as well

* Assist. Prof. PhD at Shumen University, Department of English Studies, Shumen, Bulgaria, e-mail: d.stoycheva@shu.bg. 
as to create some new ones. The latter process can be influenced and fostered by change in the social and/ or political situation in a region or internationally. Wars, famine, prolonged period of drought or climate change can be the push factors accountable for an increase in the numbers of refugees. Consequently, the increase becomes a matter of international concern, which in its turn triggers broader media coverage on the topic.

Statistical data show that in 2013 the number of refugees was 16.7 million and " $[\mathrm{m}]$ ore than half $(53 \%)$ of all refugees worldwide came from just three countries: Afghanistan (2.56 million), the Syrian Arab Republic (2.47 million), and Somalia (1.12 million)" (UNHCR 2013, p. 3). In comparison, in 2015 there was an increase in the number of refugees with almost $50 \%$ to 21.3 million and a slight change in the top three countries sources of refugees: "the Syrian Arab Republic (4.9 million), Afghanistan (2.7 million), and Somalia (1.1 million)" (UNHCR 2015, p. 3). The trend in 2017 is of further increase. The numbers reported are significant and provoke media attention as the relocation of all these people can influence the economies of the host countries and can also cause various problems. That is why an analysis on media presentation on the topic of refugees is both interesting and challenging at the same time.

\section{Previous research in the field}

People are used to availing from the images and ideas that are readily presented to them not doubting their validity. That is especially true in cases of stereotypes about groups that are further away from the place where the stereotype has been formed. According to the sociologist Charles Hurst (2007) the lack of interpersonal relations is one of the main reasons for the development of stereotypes. The unawareness of the characteristics of the Others makes people take one feature as specific of an individual or a part of a group and automatically transfer it to the whole group or all groups on a metonymic principle (see Lakoff 1987: 94).

People usually resort to the creation of prejudices and stereotypes when they feel threatened or when they want to stimulate their own self-confidence. In this respect, refugees offer a suitable image of new public devils that the main society can stand up against and develop their positive self-esteem. Media portrayal of refugees generally has been negative (cf. Cohen 2002; Finney, Peach 2004; etc.) and the trend of presenting them as constituting a media panic continues mostly because they continue to pose risks (cf. Critcher 2008: 1139). At the same time, change in presentation can easily influence existing attitudes and can foster the establishment of new stereotypes and deal with prejudice.

The study at hand is a continuation in the wide array of research conducted on the presentation of refugees and asylum seekers in the media and marks 
a contribution in a way that it is carried on a comparative basis using articles published in the Bulgarian and the British serious press.

In 2004 the Information Centre for Asylum Seekers and Refugees (ICAR) carried a research on the presentation of refugees and asylum seekers in national and local press which found "evidence of negative, unbalanced and inaccurate reporting likely to promote fear and tension within communities across London." Shaw 2010: 4). Additionally, the report found that most evidence of this was in the national rather than the local press" (ibid.). The same trend along with "a culture of disbelief" is reported in the analysis of the publications on the topic in the Scottish press in 2001 (Mollard 2001: 4) as well as in the Irish press (Breen 2006).

A very profound study was conducted by Paul Baker and Costas Gabrielatos on a corpus of 140-million-words comprised of UK press articles published between 1996 and 2005. The study analysed RASIM (refugees, asylum seekers, immigrants) representations both synchronically and diachronically and again acknowledged the predominantly negative portrayal of the members of the groups, use of nonsensical collocations such as illegal refugees as well as the maintenance of a moral panic around this discourse which "has increasingly become the dominant discourse in the UK press" (2008: 33; see also Finney 2005: 4).

Thus, summarizing the refugee stereotypes mentioned in the studies which have been consulted for this paper, the following three can be outlined very broadly:

- "Refugees, immigrants, asylum seekers or migrants - they are all the same";

- "Refugees are a threat" (they are terrorists, they are Muslim, they are of big numbers, they carry disease);

- "Refugees are a financial burden to the host country" (they rely on welfare, they drain health service, they have more privileges than locals, they leech on society) (see Wischnak web; RedCross 2014; Mollard 2001: 9ff; Shaw 2010; Santoro 2012)

\section{Corpus and Methods of Analysis}

The corpus for current analysis is comprised of 593 articles in total covering two different time periods: October 1 - November 30, 2013 and March 23 April 23, 2017. The articles comprising the corpus are excerpted from two Bulgarian newspapers (Dnevnik and Standart) and two British newspapers (The Independent and The Guardian) which are part of the serious press in the 
two countries. The number of articles from 2013 is 348, while the number of articles from 2017 is 245 .

The difference in the number of publications can be accounted for with the fact that the first period, although longer, is closer to the beginning of the refugee crisis, while the latter period marks the current state of affairs where the total number of refugees as stated above, is significantly higher than that in 2013, however, the problem is already familiar to the general public and the initial hype and surge in publications on refugees have calmed down.

The study conducted both synchronically and diachronically provides an interesting feedback on the changing ways of media presentation which reflect and at the same time influence the existing stereotypes of refugees. To do this both the verbal and the non-verbal presentations on the topic have been analysed with focus on the descriptions of refugees and the stereotypes employed in the articles. To this goal CDA, perceived as an integrated approach to the analysis of text as well as the method that studies the ideologies conducted through text especially when analyzing topics such as presentations of racism (cf. Van Dijk 1991; Fairclough 1995) and multi-modal analysis for it "extends the study of language per se to the study of language in combination with other resources, such as images, scientific symbolism, gesture, action, music and sound". (O’Halloran 2011: 120; see also Kress, Van Leeuwen 2006) have been applied as main methods of analysis.

The aim of the analysis is to assess the changes in the stereotypical image of refugees that have occurred in the two periods of the study and how these have contributed to the intercultural awareness of the readers.

\section{Results/ Key Findings}

The corpus from 2013 shows that frequently features of one group of refugees are attributed to another group based on experience. The group a nation has more experience with provides the traits used to describe the group they have not met so far on a metonymic principle. One of the most frequently used stereotypes in 2013 was "Syrian refugees are terrorists", which mentioned the possibility of terrorists entering the country along with the refugees or the refugees themselves being terrorists. Another stereotype employed by both Bulgarian and the UK media in 2013 was the generalization that "All Syrian refugees are Muslim". Refugees were also presented as disease which can be very contagious, while yet another stereotype presented refugees as financial burden and a scare as there are more of them to come. (see Cheshmedzhieva-Stoycheva 2014)

The corpus from 2017 shows similarities as well as differences in the stereotypes the Bulgarian and the British media used in 2013. 
Refugees in both the Bulgarian and the British media are usually referred to as immigrants, asylum seekers or migrants, the last reference is used predominantly by the Bulgarian media. The lack of clarity in reference and any further definitions of the terms create the generalized idea that all people who are currently displaced are the same, they are attributed similar characteristics and are therefore treated similarly. The corpus from 2017 continues the trend observed in 2013 of generalizing the image of the migrant.

In addition, officials and far right supporters still tend to talk about refugees as a problem and they are actually treated as such: officials hint on the stereotypical association of refugees with terrorism, the possible infiltration of radicalists and imminent terrorist attacks. This threat is further supported by the continued use of descriptors such as influx, wave, surge to define the big numbers of refugees and their untamed nature through the activated water metaphor, thus associating them with a natural disaster. The same reference to immigrants in general as a natural disaster through the use of nouns such as wave, flow, stream, influx, tsunami, etc. has been observed in the headlines of bTV online publications in 2015 and 2016 (cf. Nedelcheva 2017) which is indicative of a continuing trend in presentation and in stereotypical description.

Actually, surge was not used back in 2013. The increase in the references used to present one and the same idea proves the fact that the stereotype is still alive and even developing further.

The verbs that are encountered in the corpus from 2017, such as stream, stem or curb also support the stereotype of refugees being always in big numbers. The whole idea of an elementary force released with the advent of these displaced people is further hyped by the big numbers quoted as statistical data in the articles*. Similar to the corpus from 2013, the one from 2017 features quantifiers such as hundreds and thousands which are quite generic as well as depersonifying as they present all people at the border as a homogenous mass (see also Santoro 2012: 7). The negativism to and depersonification of refugees is also evident in the speech of some of the British politicians:

[1] Even while the bodies of Syrian children were washing up on Mediterranean beaches in 2015, David Cameron conjured up "swarms" trying to "break into our country". His then foreign secretary, Philip Hammond, depicted "marauding" African migrants. People fleeing bombs, rape and persecution

\footnotetext{
* In this current issue Nedelcheva (2017) is also analyzing the use of numbers in the headlines concluding that Bulgarian online publications usually feature the use of number referring to immigrant in initial position and that the manin reason for such a choice on behalf of the authors is strive for "accuracy and exhaustiveness". Further analysis on the use of numerals and quantifiers in the Bulgarian and the British press with reference to Syrian refugees is given in Cheshmedzhieva-Stoycheva (2014).
} 
were referred to as dangerous criminals. Then there's May herself. As home secretary, she talked of asylum seekers as "foreign criminals". [...] In language and in law, May has done more than any other senior politician to shape a public intolerance towards refugees. (G/ 11.04.2017); [2] Asylum seekers are all seen as bogus - not as children, not traumatised, not in need, just freeloaders coming here to take advantage of the system." [...] "The environment has changed. People with rightwing views think it is OK to insult asylum seekers. [...]”. (G/ 03.04.2017)*

The descriptors used in the examples above add up to the paradigm of linguistic devices used to create the negative image of refugees. The examples are disconcerting for another reason as well. In addition to the descriptors used, which in some cases present refugees as insects, while in others as criminals, the articles report of a worrying trend that it is politicians who take up and use the discourse of hate and intolerance and instill in their followers negative attitudes towards refugees. The politicians presented above take high and important positions and have the necessary platform to make themselves heard. They do not make suggestions or provide advice on how to deal with the phenomenon but label and stigmatize people whom they, in all probability, have not even met. In this respect, media at least try to present the other side of the coin appealing to the humanitarian aspect of the problem and the tragedy involved, which is really great, bearing in mind the fact that $52 \%$ of refugees worldwide are children (cf. UNCR web).

The stereotype of the threatening refugee is also conveyed through the use of military lexis which implicitly hints on the idea that refugees are enemies who have to be fought. The borders where refugees are halted are described as frontlines, both the Bulgarian and the British media use the term offensive as in launch an offensive in order to describe the activities undertaken to deal with the influx of refugees.

The British media features examples such as [3] "The story, it seems, is a perfect metaphor for the crisis $-1,000$ refugees to 100 villagers, an overwhelming invasion" (G/ 19.04.2017). In addition, Bulgarian media talk about refugees that are captured, which is connotative of the idea of a hunt. If we have to step a bit further into the analysis of the implications all these descriptors might have, we can also state that the stereotype that is being forged, is of refugees as animals that have to be stopped or caught.

During the analysed period Bulgarian media extensively talked about The Regulation on the Integration of Refugees which was about to be altered. The discourse about the law inevitably included the idea of close-examination of

* Italics in the examples are included by the author 
every single case of asylum application and assessment of the degree of national security threat that refugees pose (cf. Dn/ 08.04.2017; St/ 05.04.2017).

In the extra textual reality, the various terrorist attacks support the continued existence of the stereotypical association between immigrants and terrorism:

[4] Polish PM: London terror attack is about Britain's refugee policy $/ \mathrm{h} / \mathrm{It}$ is 'impossible not to connect' terror and migration, says right-wing politician $/ \mathrm{sh} /[\ldots]$ It has since emerged that the attacker, Khalid Masood, was born in Kent as Adrian Russell Elms, before later changing his name. [...] French National Front leader Marine Le Pen told both BFM TV and RMC radio: "The problem we have nowadays is this form of low-cost terrorism". She added "we must control our borders". (I/ 24.03.2017); [5] Australia refuses entry to 500 Syrian refugees 'on security grounds' /h/ Immigration minister says Westminster terror attack shows Australia is right to be cautious about who it lets into the country/sh/ (I/ 23.03.2017); [6] Mr Trump, however, has accused Syrian refugees of threatening Americans' safety [...]. At a campaign event last year, Mr Trump even went as far as to say he would look in the face of refugee children and tell them, "You can't come." He added that they could be a "Trojan horse" for Isis to get into the US. (I/ 07.04.2017)

Still, as it becomes evident from the examples, it is politicians, namely rightwing politicians again who use the reference and strengthen the stereotype. The idea of converts, supporting ISIS entering the continents disguised as refugees, is presented through the association of refugees with a Trojan horse. This reference was also used in Bulgarian media discourse in 2012 and in British media discourse in 2015 but in relation to Muslims living amongst Christians (cf. Cheshmedzhieva-Stoycheva 2012, 2015). The usage shows the transfer of features from one group of Others, i.e. Muslims, to another, i.e. refugees. It also hints on the existence of the stereotype that refugees are Muslim. Thus, the vicious circle of references is complete: Muslim - refugees - terrorists.

Bulgarian media reports the same association:

[7] [...] the increasing drought and famine on the continent could have very serious consequences, including a new wave of migrants to Europe and a possible increase in the support for Islamic extremist groups (Dn/ 29.03.2017)*; [8] Many child asylum seekers are aged between 15 and 18. "This is a group of children who are very vulnerable and could be very easily trapped by jihadist ideology," Jourová said. (G/ 12.04.2017).

In addition, the images that are usually present in support of an article in their majority show images of men or groups of men, sometimes bare-footed, other

* Translations of the examples from the Bulgarian newspapers Standart and Dnevnik are done by the author. 
times poorly dressed, lining in front of the offices of refugee agencies. Although there are also some older men to be seen, the majority of the refugees shown are men in their twenties or thirties. Women and children are very rarely seen. Exceptions to this trend are observed only in articles talking about integrated refugees. Thus the stereotype implicitly conveyed through the non-verbal element, supports the observation made in ICAR Briefing of the "threatening young male" (Santoro 2012). In example [7], though, the non-verbal component is a camp which is in a very poor condition and one can see women with headscarves standing here and there, while the second picture contains mostly women and children posing at the camera. The reason for the exception to the general trend is to highlight the contrast between the real situation and the allegations that the increased number of refugees would provide additional live fuel for terrorist groups.

The accounts of self-proclaimed vigilantes in Bulgaria who go refugee hunting along the southern border, i.e. Dinko: [9] 'They say they weren't dangerous... How would you like it if this happens to you, too?' (St/ 18.04.2017) as well as the accounts of Kurdish-Iranian boy beaten to death in Croydon, UK in April 2017 simply because the attackers found out that he is a refugee, confirm the plausibility of said connotation in the minds of the far-rights and also speak of the effect the words of the politicians had on common like-minded people.

We cannot but agree with Greenslade who states that "newspapers appeal to deep-seated racist and/or xenophobic views among their readerships. [...] To put the problem in perspective, we have to see it in terms of not only trying to change the media's agenda but also trying to change the mindset of their audience." (Greenslade 2005: 29). Basically, negative examples breed more negative examples and actions.

To confirm the existence of negative attitude towards refugees further, the articles show pictures of slogans or threats written on walls which feature the use of Nazi symbols. There are also cases of hate speech: [10] "get a gun and shoot the dogs". Similar to the use of swarms in [1], the latter also supports the stereotype of refugees being of a lower status and presenting a lower form of life that can be eliminated:

[11] "More innocent European lives sacrificed on the altar of diversity. DAMN YOU, MIGRANTS!!!” read one. Another shared graphic photographs of the bloodied bodies of victims lying on a Stockholm road - against the wishes of their families. The caption read: "Stockholm terror attack victim. This is what the roaches from the Middle East are causing." (I/ 08.04.2017).

This stereotype is also enhanced by the idea that refugees are backward, uncivilized and savage. This stereotype is very prominent in articles presenting refugees' lives in the camps. There are reports of unrest, high crime rate, sexual abuses predominantly of minors. 
Whenever there is a fight, it is between feuding groups of refugees who usually use stones or knives to settle their disputes. There are also reports of refugees damaging camps on purpose:

[12] Officials believe the fire was the result of arson. Several men at the sports hall said they had seen people deliberately spilling oil from the cooking stoves that were in most huts, and setting fire to it. "They told the women and children to get out, and then they set the huts alight," said Ali, 21, from Kabul. (G/ 11.04.2017).

Such reactions are taken as a justification for the activation of a stereotype, which is quite new - the one of the ungrateful refugee.

The cultural aspect that is considered uncivilized and which is mentioned in the media is early marriage:

[13] Justice Minister Haiko Maas has proposed the new measures because of the hundreds of minor asylum seeking girls who are married to mature husbands when they arrive. [...] The biggest ethnic group among them were Syrian kids (664), 157 were from Afghanistan, 100 from Iraq and 65 from Bulgaria (Dn/ 15.04.2017)

In addition to the accounts of minor girls marrying older men, there are a number of articles talking about the sexual abuse children suffer in camps. Most of these articles talk about camps in Greece and the verbal part of the presentation is enhanced by the image of a small girl standing with her back turned towards the camera looking through the wire fence. The image is very strong as the girl, who is said to be 4 years old, looks vulnerable - she is alone, dressed in ragged dirty clothes, without protection, hoping to get across. At the same time the idea about the rest of the refugees is associated with lust. The latter brings reminiscences of the stereotype of the sexual Other coming from the Orient (cf. Said 1999), which is directly expressed in the derogatory label an anchor, i.e. Tomi Lahren, used in one of her shows: [14] Lahren, who once labelled refugees "rapeugees" [...] (I/ 27.03.2017). Going a few months back, to the events in Cologne on the New Years' Eve, one can say that the label is justified, however, public figures and journalists should be aware of the power they have in their hands through the use of language and the consequences the use of particular words can have not only for those they denote but also for those who receive them.

The role of the media and their influence on the images created is also discussed:

[15] I notice that most stories of asylum by western journalists fall into the same trap of condescension: flattening their subjects into simple creatures of suffering and good intention. [...] If it is a dehumanising lie to suggest that 
all refugees are criminals, as the rightwing press seems content to do, it is no less a lie to depict them as hapless victims. My own experiences suggest that refugees are as diverse as any other randomly assembled group of people. [...] (G/ 19.04.2017).

The example clearly shows the discrepancy between the image created by either right-wing or left-wing papers and the image which is established as a result of direct contact with refugees. It also hints on a tendency that very frequently observed when a part of society wants to present themselves as open-minded and open to difference. Rather than being empathic and trying to understand the Other with all his/ her traditions, habits and other cultural specificities they show sympathy in a way that is not useful to the refugees themselves. They are presented as good-natured but numb. Similar to other ethnic minority groups their voice is not heard and they do not have a say in the matters that are of their concern. Thus, decisions are "taken away from them" (Pupavac 2005: 2) and made for them, which in its turn strengthens the idea that they are "simple creatures" who are incapable of fending for themselves. Consequently, people often jump into the conclusion that not being capable of anything, refugees would leech on the welfare system and would avail from opportunities not feasible to locals which, naturally, leads to frictions between locals and refugees and gives rise to intolerance and fears of reverse discrimination:

[16] In an interview for Darik Radio the Social Minister Galab Donev gave the assurance that refugees would not have more privileges than Bulgarians themselves [...] He also stressed that all foreigners who have been granted asylum or international protection have rights equal to the Bulgarian citizens and would not be granted any privileges (St/ 09.04.2017); [17] "Of course," says a pensioner, "Syrians suffer and need to be helped, but it's not normal that refugees are immediately given comfortable housing, whereas some locals are kept on waiting lists." He then names three local towns where he believes refugees have settled. After a quick check, it turns out none of them has had any arrivals. (G/22.04.2017).

The idea of reverse discrimination is obvious in the example from the British media as well. This time the opinion is structured as apparent admission (see Van Dijk 1991) which is used by people when they do not want to appear biased or prejudiced especially in front of people they do not know. Still, the fact that the independent clause after the coordinating conjunction "but" shows the perceived contrast between locals and refugees in which the latter are depicted as those who receive preferential status, makes the discriminatory attitude easy to tell. In addition, the interviewed person uses as evidence for his words hearsay rather than facts which turns out to be untrue.

On April 04, 2017 The Guardian published an article which shares from first person the experience an Iranian refugee had in the UK, the USA, and some of 
the other countries she has gone through and the stereotypes she has encountered in her life. The article is eye-opening as it presents the experience of a person who is considered the Other and who is the one subjected to all stereotypes discussed above.

Implicitly the article suggests that refugees should be grateful to their host countries, that they should try to blend in and in a way reject their cultural uniqueness: [18] "refugees should shed their old identities and be eternally thankful" (G/ 04.04.2017). The conclusion of the article is also worth looking into: [19] "The refugee has to be less capable than the native, needier; he must stay in his place. That's the only way gratitude will be accepted. Once he escapes control, he confirms his identity as the devil." (G/ 04.04.2017) All this boils down to refugees proving they are worth the trust they receive being admitted into the country of their choice, proving they are "a good bet" (G/ 04.04.2017).

The article, through this personal story traces out the whole process of stereotype formation and the way stereotypes are passed from one generation to the next as well as the change from prejudice to acceptance of the Other which is concomitant with the refugees' fitting in the society. The notion that an assimilated refugee is a good refugee is further supported by quotes of the speech of the German Chancellor Angela Merkel published in Dnevnik:

[20] Merkel advised refugees to take interest in German culture and live in the countryside $/ \mathrm{h} /[\ldots]$ We expect those who come here to obey our laws and to be a bit more interested in our life' [...] The Chancellor added that newcomers in Germany should accept the values that the country is founded on - tolerance, openness, religious freedom and freedom of speech" (Dn/ 01.04.2017); [21] "We have brought people here who have passed security checks, and they will contribute significantly to Australian society," he said. "They will be good Australians they will work hard and they will educate our children - they are the migrants we want coming to our country." (I/ 23.03.2017).

The last two examples are built around the opposition Us vs. Them and the distinction between what is considered good and what bad. Naturally, everything considered good is part of Us, while the implicit suggestion remains that what They have is negative. Thus, the acceptance refugees receive is conditional - they are accepted only if they adopt the values and the culture of the host country. These examples touch on the fact that tolerance is sometimes equal to an insult as it does not acknowledge the culture of the Other and therefore its exhibition does not lead to recognition. Naturally, laws have to be obeyed in order to maintain the equilibrium in society but for it to function as a whole, differences should be recognized. The way to do it is by showing more good examples of refugees that are not taken solely as exceptions to the rule. 


\section{Conclusion}

In conclusion, it can be stated that the resort to primarily negative stereotypes in the Bulgarian and British media observed in 2013 continues in 2017 as well. The majority of the stereotypes associated with refugees which were observed in 2013 continue to be employed in publications in 2017, i.e. refugees pose a threat (to the national security, to the economy or in general), refugees are a problem that has to be dealt with; refugees are savage. A somewhat new stereotype which has not been observed in 2013 is the one saying that the integrated/ educated refugee is a good refugee who can contribute positively to the host society.

The pictures used in the articles tend to present squalid camps, people in rags or dressed poorly which connotes to the image of a victim that is sometimes attributed to refugees. This marks the other extreme in refugees' presentation. Rather than being empathic with refugees' plight, journalists go into sympathy which is not very helpful to the refugees themselves. This form of presentation is more characteristic of the British media, while the Bulgarian ones are more scarce in their resort to visual devices. Another characteristic of the nonverbal part of the articles published in the media is the general use of images of primarily twenty, thirty-something men which focus on the other stereotype associated with refugees that they are threatening and backward. In addition, based on the various accounts of sexual abuses in the camps, the stereotype of the sexual Other also gets activated. Together with the generalization claiming that refugees are terrorists in disguise, the stereotype of the sexual Other links refugees with Islam thus establishing a vicious circle among the three terms refugees - terrorists - Muslim.

All these negative stereotypes, which are also promoted by the politicians, have negative influence on rightwing people who are easily incited into acts of racism against refugees. Refugees are also expected to fit in by accepting not only the laws but also the culture of the host country. Thus the image of the good refugee is someone who has accepted the norms of the host country, has found a job, does not cause problems, does not speak out, makes positive contributions to society and is eternally thankful.

The paper presents an attempt, albeit far from being exhaustive, at the analysis of the stereotypes and prejudices about refugees that are encountered on the pages of the analysed newspapers. The research can be broadened and in addition, probably made more representative of the general stance of the British and the Bulgarian press, with the inclusion of analysis on papers such as The Daily Mail and The Daily Telegraph, which are representative of the not so liberal press in the UK. The Bulgarian newspapers which can provide a similar twist are $\underline{24}$ chasa and Monitor. 


\section{References:}

Breen 2006: Breen M. J. Enough Already: Empirical Data on Irish Public Attitudes to Immigrants, Refugees and Asylum Seekers. - In: Breen M, Devereux E., A. Haynes (eds.). Media and Migration. The Dialogue Series. UCSIA. Antwerp.

Cheshmedzhieva-Stoycheva 2012: Cheshmedzhieva-Stoycheva D. Cases of Racism against the Majority: Examples from the Bulgarian and the British Press. - Godishnik na Shumenski Universitet. Fakultet humanitarni nauki. Vol. 23. Shumen: Shumen University Press. 182-213.

Cheshmedzhieva-Stoycheva 2014: Cheshmedzhieva-Stoycheva D. A New Public Scare: Syrian Refugees in Some Bulgarian and British Newspapers. - In: Dobrev D., H. Trendafilov (eds.). Studia Hungaro-Bulgarica. Vol. 3. Sumen-Szeged. 123-140.

Cheshmedzhieva-Stoycheva 2015: Cheshmedzhieva-Stoycheva D. Je Suis Muslim: The Image of Muslims in a Bulgarian and a British Newspaper. - Lodz Papers in Pragmatics 11.1. 105-126.

Cohen 2002: Cohen S. Moral Panics and Public Devils. The Creation of the Mods and Rockers. 3rd edition. Routledge.

Critcher 2008: Critcher C. Moral Panics Analysis: Past, Present and Future. - Sociology Compass 2/4. Journal Compilation. Blackwell Publishing Ltd. 1127-1144.

Fairclough 1995: Fairclough N. Critical Discourse Analysis: The Critical Study of Language. London, New York: Longman.

Finney 2003: Finney N. The Challenge of Reporting Refugees and Asylum Seekers: ICAR Report on Regional Media Events Organised by the PressWise Refugees, AsylumSeekers and the Media (RAM) Project. ICAR, The PressWise Trust. < http://www. mediawise.org.uk/wp-content/uploads/2011/03/Challenge-of-reporting.pdf $>$. [Accessed 30 June 2017]

Finney 2005: Finney N. Factsheet - Key Issues: Public Opinion on Asylum and Refugee Issues. ICAR.

Finney, Peach 2004: Finney N., E. Peach. Attitudes towards Asylum Seekers, Refugees and Other Immigrants: A Literature Review for the Commission for Racial Equality. London: Commission for Racial Equality; Information Centre about Asylum and Refugees in the UK. < https://web.archive.org/web/20140516161007/http://www.icar. org.uk/asylum_icar_report.pdf $>$ [Accessed 30 June 2017]

Gabrielatos, Baker 2008: Gabrielatos C., Baker P. Fleeing, Sneaking, Flooding. A Corpus Analysis of Discursive Constructions of Refugees and Asylum Seekers in the UK Press, 1996-2005. - Journal of English Linguistics. Vol. 36 (1), March. 5-38.

Greenslade 2005: Greenslade R. Seeking Scapegoats. The Coverage of Asylum in the UK Press. - Asylum and Migration Working Paper 5. May. Institute for Public Policy Research.

Hurst 2007: Hurst Ch. E. Social Inequality: Forms, Causes, and Consequences. 6th ed. Boston: Pearson Education, Inc.

Kress, Van Leeuwen 2006: Kress G., T. Van Leeuwen. Reading Images: The Grammar of Visual Design. 2nd edition. Routledge.

Lakoff 1987: Lakoff G. Women, Fire, and Dangerous Things: What Categories Reveal About the Mind. Chicago: University of Chicago Press. 
Mollard 2001: Mollard C. Asylum: The Truth behind the Headlines. UK Poverty Programme, Oxfam.

Nedelcheva 2017: Nedelcheva S. Crossing Borders on the Balkan Route: Representation of Migration in Online News. - In: Todorova et al. (eds.). Crossing Borders and Bridging Gaps in English Language Teaching and Research. Series in Linguistics, Culture and FLT, 2017 (1). 53-70.

O’Halloran 2011: O’Halloran K. L. Multimodal Discourse Analysis. - In: Hyland K., B. Paltridge (eds.) The Continuum Companion to Discourse Analysis. Continuum International Publishing Group. 120-137.

Pupavac 2006: Pupavac V. New Issues in Refugee Research. Research Paper No. 128 Refugees in the 'Sick Role': Stereotyping Refugees and Eroding Refugee Rights. Policy Development and Evaluation Service. United Nations High Commissioner for Refugees.

RedCross 2014: Asylum seekers: 13 things you should know Frequently Asked Questions. The Power of humanity. 111 years of people helping people. $<$ http://www.redcross.org. au/files/20141103_Asylum_seekers_13_things_you_should_know_FINAL_LR.pdf > [Accessed 30 June 2017]

Said 1979: Said E. W. Orientalism. New York: Vintage Books.

Santoro 2012: Santoro C. ICAR Briefing, Asylum Seekers, Refugees and Media'. $<$ http:// www.icar.org.uk/Asylum_Seekers_and_Media_Briefing_ICAR.pdf $>$ [Accessed 30 June 2017]

Shaw 2010: Shaw I. S. Asylum Seekers and Refugees: FAQs, Myths ... and the Facts. $2^{\text {nd }}$ edition. Bristol City Council.

UNHCR 2013: Global Trends. Forced Displacement in 2013. - UNHCR The UN Refugee Agency. < http://www.unhcr.org/statistics/country/5399a14f9/unhcr-global-trends-2013. html $>$ [Accessed 30 June 2017].

UNHCR 2015: Global Trends. Forced Displacement in 2015. - UNHCR The UN Refugee Agency. < http://www.unhcr.org/statistics/unhcrstats/576408cd7/unhcr-global-trends2015.html $>$ [Accessed 30 June 2017].

van Dijk 1991: van Dijk T. A. Racism and the Press. London: Routledge.

Wischnak web: Wischnak N. \#UNITECLOUD. <http://www.unitecloud.org/welfare-andrefugee-stereotypes-lets-do-this/> [Accessed 30 June 2017] 